\title{
Diagnostic Performance of Diffusion-Weighted Magnetic Resonance Imaging in Patients with Cholesteatoma
}

\author{
A. Secil Kayalı Dinç ${ }^{1}$, Lale Damgacı², Melih Çayönü', Deniz Sözmen Cılız², Süleyman Boynueğri', \\ M. Melih Șahin'1, H. Gül Hatipoğlu², T. Naciye Dogan', Adil Eryilmaz'
}

1 Ankara Numune Training and Research Hospital, Department of Otorhinolaryngology and Head Neck Surgery, Ankara, Turkey.

2 Ankara Numune Training and Research Hospital, Department of Radiology, Ankara, Turkey.

\begin{abstract}
Objective: Our aim was to evaluate the diagnostic performance of Magnetic Resonance Imaging (MRI) with diffusion-weighted images in patients with cholesteatoma. Methods: We compared the preoperative MRI findings and intraoperative microscopic examination findings in 54 patients who were operated on due to a pre-diagnosis of chronic otitis media with cholesteatoma, according to preoperative microscopic ear examination, temporal bone computed tomography (CT) and ear MRI.
\end{abstract}

Results: Fifty-four patients (18 female and 36 male) were enrolled in this study. The mean age was $36.8 \pm 17.3$ (range: 6-67). Thirty-one patients had primary surgery, whereas 23 patients had revision surgery to the affected ear (for 19 patients, the second, for 3, the third, and for 1 , the 5th operation).We found that the sensitivity of pre-operative MRI for detecting cholesteatoma was $97.7 \%$, the specificity was $77.8 \%$, and the diagnostic accuracy rate was $94.4 \%$. The rate of false negatives in MRI with diffusion-weighted images was found to be $4 \%$ in primary cases, whereas the false negativity rate with this technique was found to be $0 \%$ for revision cases.

Conclusion: We concluded that ear MRI examination with diffusion-weighted images is a significant diagnostic tool, to be used alongside preoperative history and physical examination in deciding on whether to operate, especially in patients for whom revision surgery of the ear (due to recurrent, residual, iatrogenic cholesteatoma, or squamous epithelium) is planned.

Key Words: Cholesteatoma, Magnetic resonance imaging, sensitivity, specificity.

\section{Introduction}

Cholesteatomas are epidermal inclusion cysts lined with keratinized squamous cell epithelium which can be seen in the petrous apex and mastoid cells in the middle ear ${ }^{[1]}$. "Cholesteatoma" is in fact a misnomer. Although the name might suggest a connection with the gallbladder, fat or a neoplasm, it is, in fact, none of these things. In this disease, desquamated epithelium generated by an ectopic basal germinative layer, along with keratin from the stratum corneum, accumulates within the anatomical structures involved. Enzymes secreted in the aftermath of this process cause destruction of the bone. The clinical presentation is characterized by chronic infection ${ }^{[2,3]}$.

Although cholesteatomas are not neoplasms per se, their erosive effect may cause osteolysis in the middle ear, while their expansive tendency may present as cerebral displacement at the cranial base ${ }^{[4]}$. Treatment, in this case meaning surgical intervention, is therefore essential. The guiding principle for surgery is to remove the lesion in its entirety, ensuring no remaining disease is left, and to perform a reconstruction in such a way as to prevent recurrence ${ }^{[2]}$.

It is important to establish the diagnosis of choleste-
Correspondence: Ayşe Seçil Kayalı Dinç

Ankara Numune Training and Research Hospital, Department of Otorhinolaryngology and Head Neck Surgery, 06230, Altındağ, Ankara, Turkey.

e-mail: secilkayali81@yahoo.com

Received: 30th, November, 2018; Accepted: 10th, December, 2018
Online available at: www.entupdates.org

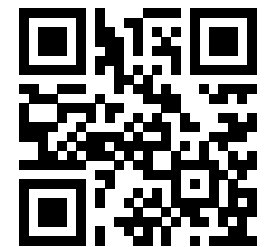


atoma pre-operatively to determine the surgical method to follow, and also to allow effective follow-up post-operatively. Although Computerized Tomography (CT) can provide significant information regarding the region, it is known to be inadequate for differentiating between cholesteatoma and other lesions involving soft tissue. For this reason, Diffusion Weighted Magnetic Resonance Imaging (DWMRI) has come to assume a significant role in the differential diagnosis of cholesteatoma ${ }^{[5-7]}$.

The aims of our research were to consider the results of DWMRI and any intraoperative findings in those patients who were diagnosed with cholesteatoma via DWMRI within our clinic and who subsequently underwent surgical treatment. In this way we aimed to investigate the diagnostic effectiveness of DWMRI.

\section{Materials and Methods}

This retrospective study included 54 patients and 54 separate ear operations. The operations were performed due to a pre-diagnosis of chronic otitis media with cholesteatoma, as determined by preoperative microscopic ear examination, temporal bone computed tomography (CT) and temporal bone magnetic resonance imaging (MRI) results. The data indicate 31 patients were operated on for the first time, whilst 23 patients had revision surgery on the ear affected by chronic otitis media.

In this study, we compared the preoperative MRI findings and intraoperative microscopic examination findings during tympano-mastoidectomy. All the patients underwent pre-operative MRI examination. The approval of the Local Ethics Committee was obtained (E-17/1237), and all investigations were performed in accordance with the Declaration of Helsinki on biomedical studies involving human subjects.

\section{Radiological examination}

All the MRI examinations were obtained with a $1.5 \mathrm{~T}$ MR unit (Excite, GE Medical systems, Milwaukee, Wisconsin, USA). The gradient power was $33 \mathrm{mT} / \mathrm{s}$. Axial T1-weighted, T2- weighted, 3D-FIESTA, and contrast-enhanced axial and coronal T1-weighted sequences were used for routine temporal MRI, and gadolinium chelate at a dose of $0.2 \mathrm{~mL} / \mathrm{kg}$ was used as contrast agent. The parameters for imaging employed in the study were as follows: T1-weighted (Figure 1) (TR, $500 \mathrm{~ms}$; TE, $15.7 \mathrm{~ms}$; slice thickness, $3 \mathrm{~mm}$; interslice gap, $0.5 \mathrm{~mm}$; field of view, 20 $\times 20 \mathrm{~cm}$; matrix, $320 \times 224$; excitations, 3); T2-weighted

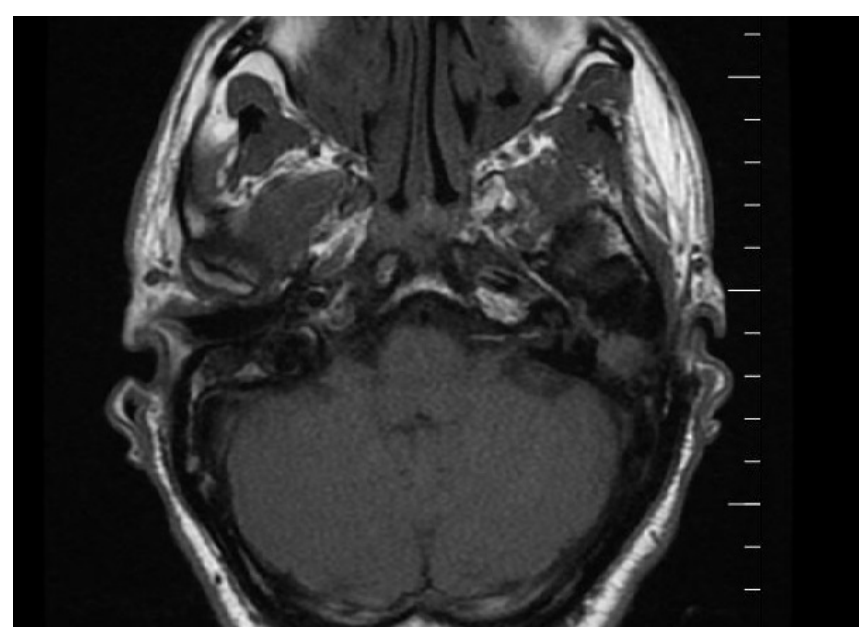

Figure 1. Cholesteatoma of the left ear, MRI-T1 axial slice

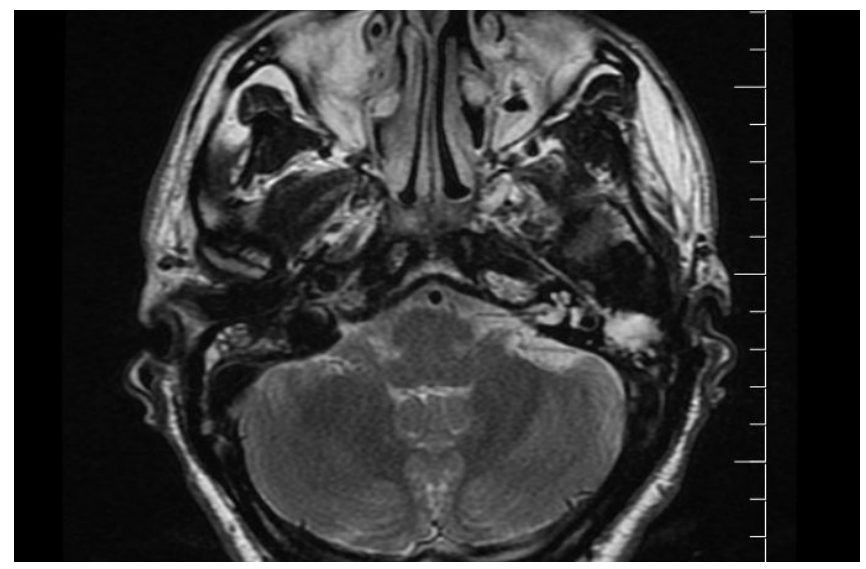

Figure 2. Cholesteatoma of the left ear, MRI-T2 axial slice

(Figure 2) (TR, $3000 \mathrm{~ms}$; TE, $104.8 \mathrm{~ms}$; slice thickness, 3 $\mathrm{mm}$; interslice gap, $0.5 \mathrm{~mm}$; field of view, $20 \times 20 \mathrm{~cm}$; matrix, $320 \times 224$; excitations, 3); 3D-FIESTA (TR, $4.8 \mathrm{~ms}$; TE, $1.4 \mathrm{~ms}$; slice thickness, $0.5 \mathrm{~mm}$; field of view, $18 \times 18$ cm; matrix, $352 \times 192$; excitations, 4). T2-weighted images were obtained with fast spine echo (FSE) sequences. Fluid-attenuated inversion recovery (FLAIR) (repetition time, $8.402 \mathrm{~ms}$; echo time, $95.5 \mathrm{~ms}$; slice thickness: $5 \mathrm{~mm}$; interslice gap: $1.5 \mathrm{~mm}$, matrix: $288 \times 192$; excitations, 1 ) images and diffusion-weighted sequence images (repetition time, 10,000 ms; echo time, $85.8 \mathrm{~ms}$; slice thickness: $4 \mathrm{~mm}$; interslice gap: $1 \mathrm{~mm}$; matrix: $128 \times 128$ ) were obtained in patients to enable differential diagnosis of cholesteatoma. Diffusion-weighted (DW) sequences were performed with echo planar single shot spin echo imaging with $b$ values of 0 and $1000 \mathrm{~s} / \mathrm{mm}^{2}$ (Figure 3). Diffusion gradients were applied in three orthogonal directions to generate three 


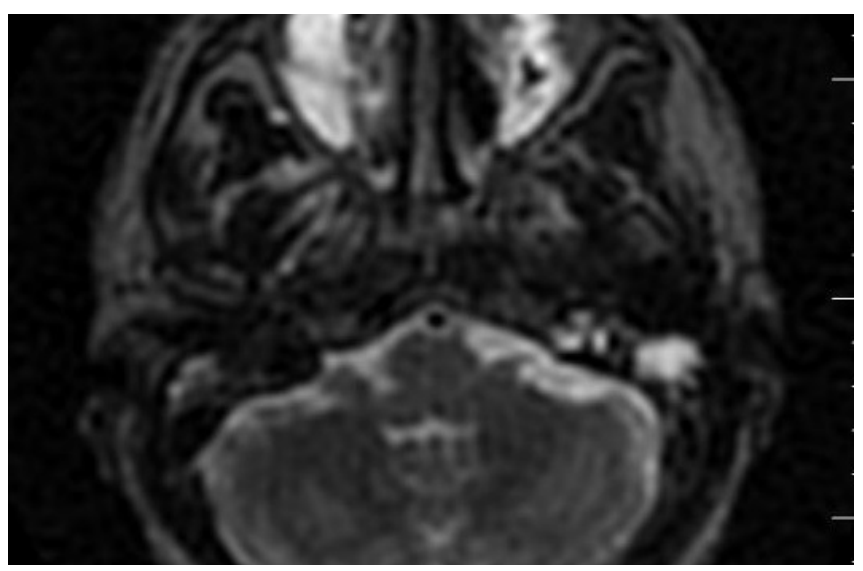

Figure 3. Cholesteatoma of the left ear, MRI- DWI-Propeller slice

sets of diffusion-weighted imaging ( $\mathrm{x}, \mathrm{y}, \mathrm{z}$ axes). Apparent diffusion coefficient (ADC) values were automatically calculated and axial PROPELLER DWI (NON-EPI) of the temporal bone was acquired for the cases.

\section{Statistical Analysis}

The SPSS 16.0 application was used to perform all the required statistical analyses. The surgical findings were compared with pre-operative MRI findings to calculate the sensitivity, specificity, diagnostic accuracy ratio and predictive values for MRI examination in detecting cholesteatoma.

\section{Results}

Fifty-four patients (18 female and 36 male) were enrolled in this study. The mean age was $36.8 \pm 17.3$ (range 6-67 years). Following pre-operative ear microscopic examination, we ascertained that 19 patients had a perforated tympanic membrane, 17 patients had attic adhesion of the tympanic membrane with destruction of the postero-superior segment of the bony ear canal, 6 patients had pars-tensa adhesion of the tympanic membrane, 2 patients had normal tympanic membranes, and 10 patients had evidence of previous surgery (mastoidectomy) affecting the canal wall. Furthermore, during the preoperative microscopic ear examination, squamous epithelium from 16 cases was aspirated. No squamous epithelium was aspirated in 38 cases. During the course of mastoidectomy, 45 cases were discovered to have cholesteatoma formation or squamous epithelium in the mastoid air cells, and 9 had granulation tissue. The mean dimensions of cholesteatoma as visual- ised by MRI were $10.1 \mathrm{~mm}$ by $9.5 \mathrm{~mm}$ (range $2 \mathrm{~mm}-25 \mathrm{~mm}$ in both directions).

Thirty-one patients had primary surgery, whereas 23 patients had revision surgery to the affected ear (for 19 patients, the second, for 3, the third, and for 1, the 5th operation).

Comparing pre-operative MRI with the intraoperative findings, we found that the sensitivity of pre-operative MRI for detecting cholesteatoma was $97.7 \%$, the specificity was $77.8 \%$, and the diagnostic accuracy rate was $94.4 \%$. The cases were then grouped into "primary operated" and "revision", and the sensitivity, specificity, and diagnostic accuracy rates for each group were then calculated. We found that the sensitivity, specificity, and diagnostic accuracy rates for the primary surgery group were $96 \%, 83.3 \%$ , and $93.5 \%$, respectively, whereas the sensitivity, specificity, and diagnostic accuracy rates for the revision surgery group were $100 \%, 67 \%$, and $95.6 \%$, respectively.

\section{Discussion}

Although it has been more than 300 years since cholesteatoma first appeared as an entity in the medical literature and despite current technology being amply provided with advanced sectional imaging techniques, difficulties are still encountered in the diagnosis of cholesteatoma ${ }^{[8]}$.

Many clinicians use high resolution computerized tomography in the diagnosis of cholesteatoma. Ossicular erosion, fistulas of the lateral semicircular canal or destruction of the tegmen are the principal findings leading to consideration of this diagnosis in interpreting high resolution CT results. Additionally, with CT, important information is obtained regarding the ossicular chain, facial nerve, semicircular canal, and temporal bone landmarks. On the other hand, with cholesteatoma, there are difficulties in differentiating amongst soft tissue densities such as mucoid secretion and granulation tissue in the middle ear and mastoid air cells ${ }^{[5-7,9]}$. Due to the associated difficulties in differential diagnosis of soft tissue masses, clinicians have begun to prefer the use of MRI while undertaking differential diagnosis of this disease. In some studies, the sensitivity of conventional MRI in the diagnosis of cholesteatoma was found to be $57-79 \%$, while its specificity was found to be $63-71 \%{ }^{[5-7]}$. Thickening caused by mucosal inflammation and granulation tissue exhibits the same signal characteristics in conventional MRI sequences. The distinction between granulation tissue and cholesteatoma through the use of contrast enhancement is also challenging due to the 
absence of vascularization within cholesteatomas. This underlines the fact that conventional MRI protocols consisting of T1 and T2 weighted images are not very effective in the differential diagnosis of cholesteatoma. This situation has led to an increasing emphasis on the use of DW MRI rather than conventional MRI for effective differential diagnosis of cholesteatoma.

In DW MRI, the image is based on the freely flowing characteristic of water as it diffuses within normal tissue. The combination of the $\mathrm{T} 2$ effect and high signal intensity from diffusion of water molecules whose movement is restricted play a role in the imaging method ${ }^{[1,10,11]}$.

In a meta-analysis by $\mathrm{Li}$ et al. including a total of 342 patients in 10 studies, the pooled specificity and sensitivity rates of DWMRI in cholesteatoma diagnosis were both calculated to be $94 \%{ }^{[12]}$.

Following this meta-analysis by Li et al., Lingam et al. found the pooled sensitivity to be $91 \%$ and pooled specificity $92 \%$ in the use of DW MRI for diagnosis in their meta-analysis of 26 studies in which data from 1152 patients with middle ear cholesteatoma were included ${ }^{[13]}$.

In our study, in the comparison of DWMRI results with intraoperative findings for the diagnosis of cholesteatoma, the sensitivity of DWMRI was found to be $97.7 \%$ and the specificity $77.8 \%$. Additionally, the rate of accuracy of diagnosis by DWMRI was $94.4 \%$, whilst the rate of false negativity was $2.2 \%$. These results were in accordance with the findings in the literature. Furthermore, although it has been reported elsewhere that MRI detection of foci of cholesteatoma smaller than $5 \mathrm{~mm}$ may be insufficient, in our cases it was observed that even the $2-3 \mathrm{~mm}$ foci of cholesteatoma or squamous epithelium located in the middle ear or mastoid air cells were reported correctly. DW MRI scanning, moreover, had similar sensitivity, specificity, and rates of accuracy of diagnosis to those in primary cases, in the identification of cholesteatoma and squamous epithelium in cases with revision mastoidectomy. While the rate of false negatives in DW MRI scanning was found to be $4 \%$, when primary cases were evaluated separately, the false negativity ratio of this scan was found to be $0 \%$ for revision cases. Taking these findings in their entirety, we consider ear DWMRI examination as a significant auxiliary diagnostic tool along with preoperative history and physical examination in the decision whether to proceed to surgery, especially in patients for whom revision surgery of the ear (recurrent, residual, iatrogenic cholesteatoma, or squamous epithelium) is planned.

\section{Conclusion}

In the preoperative period, the ability of DWMRI to assist in the differential diagnosis of chloesteatoma is a significant factor to bear in mind. Even though it is a non-malignant lesion, cholesteatoma can produce catastrophic clinical consequences. Diffusion weighted imaging should definitely be added to the sequences of conventional MRI. In the evaluation of residual and recurrent cholesteatoma, we believe that a DW MRI examination performed prior to deciding on surgery, together with medical history and physical examination findings will provide significant guidance and enable the avoidance of unnecessary surgery. These results should be supported with further multi-centre studies that also include a wider population of patients.

\section{Acknowledgements}

\section{Scientific Responsibility Statement}

The authors declare that they are jointly responsible for the article's scientific content including the study design, data collection, analysis and interpretation, the writing-up and scientific review of the contents and have given their collective approval to the final version of the article.

\section{Funding}

There is no funding to declare.

\section{Conflicts of interest}

None of the authors has received any type of financial support that might be construed as a potential conflict of interest regarding the manuscript or its submission. 


\section{References}

1. Aikele P, Kittner T, Offergeld C, Kaftan H, Hüttenbrink KB, Laniado M. Diffusion-weighted MR imaging of cholesteatoma in pediatric and adult patients who have undergone middle ear surgery. AJR Am J Roentgenol 2003;181:261-5. Doi: 10.2214/ajr.181.1.1810261

2. Uzun C. Kolesteatom. Türkiye Klinikleri Cerrahi Tıp Bilimleri Kulak Burun Boğaz Dergisi 2005;1:128-34.

3. Olszewska E, Wagner M, Bernal-Sprekelsen M et al. Etiopathogenesis of cholesteatoma. Eur Arch Otorhinolaryngol 2004;261:6-24. Doi: 10.1007/ s00405-003-0623-x

4. Atsushi F, Morita S, Harada T et al. Value of T1-weighted magnetic resonance imaging in cholesteatoma detection. Otol Neurotol 2017; 38:14404. Doi: 10.1097/MAO.0000000000001558.

5. Tierney PA, Pracy P, Blaney SP, Bowdler DA. An assessment of the value of the preoperative computed tomography scans prior to otoendoscopic 'second look' in intact canal wall mastoid surgery. Clin Otolaryngol Allied Sci 1999;24:274-6. Doi: 10.1046/j.1365-2273.1999.00238.x

6. Vanden Abeele D, Coen E, Parizel PM, Van de Heyning P. Can MRI replace a second look operation in cholesteatoma surgery? Acta Otolaryngol 1999;119:555-61. Doi: 10.1080/00016489950180784

7. Kimitsuki T, Suda Y, Kawano H, Tono T, Komune S. Correlation between MRI findings and second-look operation in cholesteatoma surgery. ORL J Otorhinolaryngol Relat Spec 2001;63:291-3. Doi: 10.1159/000055760
8. Baráth K, Huber AM, Stämpfli P, Varga Z, Kollias S. Neuroradiology of cholesteatomas. AJNR Am J Neuroradiol 2011;32:221-9. Doi: 10.3174/ ajnr.A2052

9. Blaney SP, Tierney P, Oyarazabal M, Bowdler DA. CT scanning in "second look" combined approach tympanoplasty. Rev Laryngol Otol Rhinol (Bord) 2000;121:79-81.

10. Vercruysse JP, De Foer B, Pouillon M, Somers T, Casselman J, Offeciers $\mathrm{E}$. The value of diffusion-weighted MR imaging in the diagnosis of primary acquired and residual cholesteatoma: a surgical verified study of 100 patients. Eur Radiol 2006;16:1461-7. Doi: 10.1007/s00330-0060160-2

11. Stasolla A, Magliulo G, Parrotto D, Luppi G, Marini M. Detection of postoperative relapsing/residual cholesteatomas with diffusion weighted echo-planar magnetic resonance

imaging. Otol Neurotol 2004;25:879-84.

12. Li PM, Linos E, Gurgel RK, Fischbein NJ, Blevins NH. Evaluating the utility of non echo-planar diffusion-weighted imaging in the preoperative evaluation of cholesteatoma: a meta-analysis. Laryngoscope 2013;123(5): 1247-50. Doi: 10.1002/lary.23759

13. Lingam RK, Bassett P. A Meta-Analysis on the Diagnostic Performance of Non-Echoplanar Diffusion-Weighted Imaging in Detecting Middle Ear Cholesteatoma: 10 Years On. 2017 38(4):521-8. Doi: 10.1097/ MAO.0000000000001353

This is an open access article distributed under the terms of the Creative Commons Attribution-NonCommercial-NoDerivs 3.0 Unported (CC BY- NC-ND3.0) Licence (http://creativecommons.org/licenses/by-nc-nd/3.0/) which permits unrestricted noncommercial use, distribution, and reproduc- tion in any medium, provided the original work is properly cited.

Please cite this article as: Kayalı Dinç A. S., Damgacı L, Çayönü M, Sözmen Cılız D, Boynueğri S, Şahin M. M., Hatipoğlu H. G., Dogan T. N., Eryilmaz A., Diagnostic Performance of Diffusion-Weighted Magnetic Resonance Imaging in Patients with Cholesteatoma. ENT Updates 2018;8(3): 180-184. 